\title{
Association of the transfer coefficient of the lung for carbon monoxide with emphysema progression in male smokers
}

\author{
F.A.A. Mohamed Hoesein*, P. Zanen*, B. van Ginneken*, ${ }^{\#, ~ R . J . ~ v a n ~ K l a v e r e n ~}{ }^{+}$ \\ and J-W.J. Lammers*
}

ABSTRACT: A decreased transfer coefficient of the lung for carbon monoxide $(K \mathrm{CO})$ is associated with emphysema. We evaluated whether in heavy smokers, baseline $K c 0$ was associated with the progression of computed tomography (CT)-detected emphysema, and the progression of airflow limitation.

Heavy smokers, mean \pm SD $41.3 \pm 18.7$ pack-yrs, participating in a lung cancer screening trial underwent diffusion testing and CT scanning of the lungs. CT scanning was repeated after median (25th-75th percentile) 2.8 (2.7-3.0) yrs and emphysema was assessed by lung densitometry using the 15th percentile. The association between $K \mathrm{CO}$ at baseline with progression of emphysema and lung function decline was assessed by multiple linear regression, correcting for baseline CTquantified emphysema severity and forced expiratory volume in $1 \mathrm{~s}$ (FEV1)/forced vital capacity (FVC), age, height, body mass index, pack-yrs and smoking status (current or former smoker).

522 participants aged $60.1 \pm 5.4$ yrs were included. Mean \pm SD 15th percentile was $-938 \pm 19$, absolute $\mathrm{FEV} 1 / \mathrm{FVC}$ was $71.6 \pm 9 \%$ and $K \mathrm{KCO}$ was $1.23 \pm 0.25$, which is $81.8 \pm 16.5 \%$ of predicted. By interpolation, a one SD (0.25) lower $K \mathrm{CO}$ value at baseline predicted a $1.6 \mathrm{HU}$ lower 15 th percentile and a $0.78 \%$ lower FEV1/FVC after follow-up ( $<<0.001$ ).

A lower baseline $K \mathrm{CO}$ value is independently associated with a more rapid progression of emphysema and airflow limitation in heavy smokers.

KEYWORDS: Chronic obstructive pulmonary disease, computed tomography, diffusion testing, emphysema, longitudinal, spirometry

hronic obstructive pulmonary disease (COPD) is the only chronic disease with increasing mortality rates and is supposed to be the third leading cause of death by 2020 [1]. Since prevention of COPD appears to be more promising than treatment, early recognition of COPD-susceptible subjects is therefore pivotal to reducing the increasing burden of this disease.

COPD is characterised by progressive airflow limitation and consists of chronic bronchitis and emphysema. Chronic bronchitis leads to, for example, increased mucus production in the (smaller) airways causing airway obstruction, while emphysema induces airflow obstruction by loss of elastic recoil of lung tissue. Both can coincide and contribute to a greater degree of airflow obstruction. Currently, in the living subject, emphysema can only be assessed by means of computed tomography (CT) scans and lung densitometry measurements to quantify the extent of the disease. However, there are some disadvantages to CT scanning, most importantly the radiation exposure, the costs and the availability of the equipment [2].

The diffusion capacity of carbon monoxide is an easy-to-perform tool to assess the functionality of the alveolar-capillary membrane and is reported as the transfer coefficient of the lung for carbon monoxide (KCO) [3]. The KCO can be considered as the rate constant for alveolar carbon monoxide uptake and is lowered in the presence of emphysema. Holme and STOCKLEY [4] showed that a large proportion of subjects with a lowered $\mathrm{KCO}$, but with normal forced expiratory volume in $1 \mathrm{~s}$ (FEV1)/forced vital capacity (FVC) values, show radiological evidence of emphysema. A decreased KCO therefore supports a diagnosis of emphysema in patients with or without airflow

\section{AFFILIATIONS}

*Division of Heart and Lungs, Dept of Respiratory Medicine,

\#Image Sciences Institute, Dept of Radiology, University Medical Center Utrecht, Utrecht,

"Diagnostic Image Analysis Group, Dept of Radiology, Radboud University Nijmegen Medical Centre, Nijmegen, and

+Dept of Respiratory Medicine, Erasmus University Medical Center, Rotterdam, The Netherlands.

CORRESPONDENCE

P. Zanen

University Medical Center Utrecht,

HP. F. 02.333

PO Box 85500

3508 GA Utrecht

The Netherlands

E-mail: p.zanen@umcutrecht.nl

Received:

March 222011

Accepted after revision:

April 262011

First published online:

May 122011 
obstruction and may add to spirometry to establish the diagnosis of COPD [5].

However, little is known about the association between KCO and the natural course of CT-quantified emphysema and FEV1/FVC in heavy, but relatively healthy, smokers. We hypothesised that lower baseline KCO values were associated with a more rapid progression of CT-quantified emphysema and decline in FEV1/FVC. Therefore, the aim of the present study was to assess, first, the relationship between the KCO at baseline and the progression of CT-quantified emphysema, and secondly, the progression of airflow obstruction.

\section{METHODS}

\section{Participants}

The study was conducted among participants of the DutchBelgian Lung Cancer Screening Trial (NELSON) who were recruited by the University Medical Center Utrecht, Utrecht, the Netherlands, as only this centre included diffusion capacity measurements. The NELSON is a population-based CTscreening trial for lung cancer, and inclusion criteria have been published previously [6, 7]. In short, participants meeting the inclusion criteria of having smoked a minimum 20 packyrs and being fit enough to undergo potential thoracic surgery were invited to participate. Only males were included based on their high risk of developing lung cancer/COPD, as fewer females in the Dutch population have accumulated a long-term exposure to cigarettes compared with males [5]. Baseline details on smoking habits were gathered through questionnaires, which included questions about duration of smoking, number of pack-yrs smoked and smoking status at enrolment (current or former smoker). It was decided at the start that this study should provide a unique opportunity to also assess lung function and to investigate this in relation to $\mathrm{CT}$ measures. Therefore, spirometry was assessed in all individuals.

The NELSON trial was approved by the Dutch Ministry of Health on December 23, 2003, and by the institutional review board of the University Medical Center Utrecht, the Netherlands (approval number 03/040). The NELSON trial is registered at www.trialregister.nl with trial number ISRCTN63545820. Informed consent was obtained from all participants.

\section{Pulmonary function testing}

Pulmonary function tests (PFT) included FEV1, FVC, alveolar volume and $\mathrm{KCO}$, which were all carried out according to current European Respiratory Society (ERS) guidelines [8, 9]. Reversibility of airflow obstruction was not assessed. PFT was performed on the same day as the CT scan. Airflow obstruction was defined as an FEV1/FVC below the lower limit of normal (LLN) at baseline [10].

KCO measurements were performed with a MasterLab Pro (Erich Jaeger $\mathrm{GmbH}$, Wurzburg, Germany), with the singlebreath manoeuvre method; the test gas contained CO $0.25 \%$, $\mathrm{He} 9.17 \%$ with balance air. $\mathrm{KCO}$ was expressed as $\mathrm{mmol} \cdot \mathrm{min}^{-1}$. $\mathrm{kPa}^{-1} \cdot \mathrm{L}^{-1}$. A breath-holding period of $10 \mathrm{~s}$ (Jones and Meade method) and discard/sample volumes of $750 \mathrm{~mL}$ were adopted [11]. Smokers refrained from smoking from $24 \mathrm{~h}$ before the measurement; no correction for haemoglobin levels was made since this has only a very limited effect [12]. Predicted values and the LLN were calculated by using appropriate reference values [10, 13]. KCO values below the LLN were considered abnormal.

\section{CT scanning}

All participants received low-dose CT, using 16-detector multidetector computed tomography (MDCT) scanners (Mx8000 IDT or Brilliance 16P; Philips Medical Systems, Cleveland, $\mathrm{OH}$, USA), at baseline and after follow-up. Scan data were obtained in spiral mode, with $16 \times 0.75-\mathrm{mm}$ collimation and in full inspiration. No spirometric gating was applied since this does not improve repeatability of lung density measurements [14, 15]. Axial images were reconstructed with a $1.0-\mathrm{mm}$ thickness at $0.7-\mathrm{mm}$ increments. All scans were reconstructed with a soft reconstruction filter (Philips B, Siemens B30f; Philips Medical Systems, Cleveland, $\mathrm{OH}, \mathrm{USA})$ at a $512 \times 512$ matrix. Exposure settings were $30 \mathrm{mAs}$ at $120 \mathrm{kVp}$ or $140 \mathrm{kVp}$, depending on the participant's weight. This low-dose CT protocol has previously been used to quantify emphysema in COPD patients and heavy smokers [16, 17]. All CT scans were automatically analysed by software developed in-house [18]. Airways were excluded to ensure that only lung parenchyma was analysed [19].

\section{Emphysema quantification}

Severity of emphysema was based on the 15th percentile technique. This technique provides the Hounsfield Units (HU) point below which $15 \%$ of the voxels are distributed. The lower the 15 th percentile values are thus closer to $-1000 \mathrm{HU}$, the more emphysema is present. This method of emphysema quantification has been validated against pathology [20] and has been applied in multiple studies [21]. The 15th percentile was preferred to the \%-950 HU measurement [22]. However, a secondary analysis was done using the \%-950 HU as emphysema severity measure, which is defined as the proportion of low-density voxels below $-950 \mathrm{HU}$, and is reported in the online supplementary material.

\section{Statistical evaluation}

Mean \pm SD values were calculated for normally distributed data and median and 25th-75th percentile values for non-normally distributed data. Unpaired t-tests and Chi-squared tests were used to test differences between groups as appropriate. Pearson's correlations were used to establish associations between variables at baseline.

Emphysema severity (15th percentile) and FEV1/FVC at the end of the observation period were the primary end-points and were analysed by multiple linear regression analyses. KCO at baseline was the main explanatory factor. Adjustments were made for baseline 15th percentile and FEV1/FVC, age, height, body mass index (BMI), pack-yrs, and smoking status (current or former smoker). 15th percentile progression and FEV1/FVC decline were calculated by subtracting follow-up values adjusted by multiple linear regression analyses from observed baseline values. A p-value of $<0.05$ was considered significant. All statistical analyses were performed using SPSS 18 for Windows (SPSS, Chicago, IL, USA).

The mean \pm SD 15 th percentile was $-937.7 \pm 18.5 \mathrm{HU}$. Baseline KCO was significantly correlated with 15 th percentile at baseline $(\mathrm{r}=0.23, \mathrm{p}<0.001)$. Participants with an abnormal KCO $(<\mathrm{LLN})$ had significantly more $(\mathrm{p}=0.002)$ CT-quantified 
emphysema as compared to subjects with a normal KCO, $-940.1 \pm 19.0 \mathrm{HU}$ and $-935.1 \pm 17.6 \mathrm{HU}$, respectively.

\section{RESULTS}

\section{Baseline demographics, lung function and CT-quantified emphysema}

609 participants underwent follow-up CT-scanning and spirometry. Of these 609 participants, 87 were excluded due to missing or incomplete baseline KCO values, resulting in 522 participants being included in the current study. There were no significant differences in baseline age, height, BMI, pack-yrs, smoking status, spirometry results or CT-quantified emphysema severity between included participants and participants who were excluded due to missing or incomplete KCO values.

The mean \pm SD age of the participants was $60.1 \pm 5.4$ yrs and $251(48.1 \%)$ were current smokers. FEV1/FVC was $71.6 \% \pm 9.0$ of predicted and mean \pm SD KCO was $1.23 \pm 0.25$, which is $81.8 \pm 16.5 \%$ of predicted. Further baseline demographics and lung function parameters for the total study population are provided in table 1. More than half of the participants, 272 (52.1\%), had an abnormal KCO at baseline and the baseline KCO was significantly correlated with baseline FEV1/FVC ( $r=0.46$, $\mathrm{p}<0.001$ ). Demographics and lung function parameters stratified by normal and KCO <LLN are presented in table 2 . The majority of participants, $424(81.2 \%)$, had no airflow obstruction (FEV1/FVC >LLN). Of the participants with no airflow obstruction, $213(50.2 \%)$ had a lowered KCO. Figure 1 illustrates the baseline FEV1/FVC stratified by KCO $>$ LLN and <LLN.

\section{Association of Kco with progression of CT-quantified emphysema}

Median (interquartile range) follow-up time was 2.75 (2.73.0) yrs. The mean 15th percentile after follow-up was $-944.4 \pm$ 17.9 HU and the mean \pm SD progression of emphysema was $6.3 \pm 5 \mathrm{HU}$. The statistical model explained $68 \%$ of the variance in the 15th percentile after follow-up $\left(\mathrm{r}^{2}=0.68\right)$. Baseline values of FEV1/FVC, 15th percentile and KCO and smoking status

\section{TABLE 1 Baseline demographics}

\begin{tabular}{|c|c|}
\hline Subjects $n$ & 522 \\
\hline Age yrs & $60.1 \pm 5.4$ \\
\hline Height $\mathbf{m}$ & $1.78 \pm 0.07$ \\
\hline$B M I \mathbf{k g} \cdot \mathbf{m}^{-2}$ & $26.8 \pm 3.3$ \\
\hline Follow-up yrs & $2.75(2.7-3.0)$ \\
\hline Pack-yrs smoking & $41.3 \pm 18.7$ \\
\hline Current smokers $\%$ & 48.1 \\
\hline FEV $_{1} \mathrm{~L}$ & $3.35 \pm 0.72$ \\
\hline FEV $1 \%$ pred & $97.6 \pm 18.2$ \\
\hline FEV $_{1 / F V C}$ absolute $\%$ & $71.6 \pm 9.0$ \\
\hline Participants with airflow obstruction ${ }^{\#} \%$ & $98 \pm 18.8$ \\
\hline $\mathrm{Kco} \mathrm{mmol}^{-1} \cdot \mathrm{min}^{-1} \cdot \mathrm{KPa}^{-1} \cdot \mathrm{L}^{-1}$ & $1.23 \pm 0.25$ \\
\hline Kco \% pred & $81.8 \pm 16.5$ \\
\hline 15th percentile emphysema score on СТ HU & $-937.8 \pm 18.5$ \\
\hline
\end{tabular}

Data are presented as mean $\pm \mathrm{SD}$ or median (interquartile range), unless otherwise stated. BMI: body mass index; FEV1: forced expiratory volume in $1 \mathrm{~s}$; $\%$ pred: \% predicted; FVC: forced vital capacity; KCO: transfer coefficient of the lung for carbon monoxide; CT: computed tomography. "\#: FEV1/FVC < lower limit of normal.

\begin{tabular}{|c|c|c|c|c|}
\hline \multirow[t]{2}{*}{ TABLE 2} & \multicolumn{4}{|c|}{$\begin{array}{l}\text { Baseline demographics stratified by normal anc } \\
\text { transfer coefficient of the lung for carbon } \\
\text { monoxide }(K C O)<\text { lower limit of normal (LLN) }\end{array}$} \\
\hline & & Normal Kco & KCO $<$ LLN & $p$-value \\
\hline \multicolumn{2}{|l|}{ Subjects $n$} & 250 & 272 & \\
\hline \multicolumn{2}{|l|}{ Age yrs } & $60.6 \pm 5.4$ & $59.7 \pm 5.3$ & 0.067 \\
\hline \multicolumn{2}{|l|}{ Height $\mathrm{m}$} & $1.78 \pm 0.06$ & $1.78 \pm 0.06$ & 0.155 \\
\hline \multicolumn{2}{|l|}{$\mathrm{BMI} \mathbf{k g} \cdot \mathrm{m}^{-2}$} & $26.8 \pm 3.3$ & $26.8 \pm 3.3$ & 0.256 \\
\hline \multicolumn{2}{|l|}{ Follow-up yrs } & $2.75(2.7-3.0)$ & $2.75(2.7-3.0)$ & 0.325 \\
\hline \multicolumn{2}{|c|}{ Pack-yrs smoking } & $40.4 \pm 19.1$ & $42.1 \pm 18.3$ & 0.326 \\
\hline \multicolumn{2}{|c|}{ Current smokers } & $91(36.4)$ & $160(59.4)$ & $<0.001^{\bullet}$ \\
\hline \multicolumn{2}{|l|}{ FEV 1 L } & $3.40 \pm 0.68$ & $3.30 \pm 0.75$ & 0.142 \\
\hline \multicolumn{2}{|l|}{ FEV $1 \%$ pred } & $99.6 \pm 16.6$ & $95.8 \pm 19.3$ & $0.015^{\circ}$ \\
\hline \multicolumn{2}{|c|}{ FEV $1 /$ FVC absolute $\%$} & $74.4 \pm 7.4$ & $69.2 \pm 9.6$ & $<0.001^{\bullet}$ \\
\hline \multicolumn{2}{|c|}{$\begin{array}{l}\text { Participants with airflow } \\
\text { obstruction }\end{array}$} & $27(10.8)$ & $71(26.1)$ & $<0.001^{\circ}$ \\
\hline \multicolumn{2}{|c|}{ Kco $\mathrm{mmol}^{-1} \cdot \mathrm{min}^{-1} \cdot \mathrm{kPa}^{-1} \cdot \mathrm{L}^{-1}$} & $1.43 \pm 0.15$ & $1.05 \pm 0.17$ & $<0.001^{\bullet}$ \\
\hline \multicolumn{2}{|c|}{ Kco \% pred } & $95.6 \pm 9.6$ & $69.7 \pm 10.8$ & $<0.001^{\bullet}$ \\
\hline \multicolumn{2}{|c|}{$\begin{array}{l}\text { 15th percentile emphysema } \\
\text { score on CT HU }\end{array}$} & $935.1 \pm 17.6$ & $-940.1 \pm 19.0$ & $0.002^{\circ}$ \\
\hline
\end{tabular}

Data are presented as mean $\pm \mathrm{SD}$, median (interquartile range) or $\mathrm{n}(\%)$, unless otherwise stated. BMI: body mass index; FEV1: forced expiratory volume in $1 \mathrm{~s}$; $\%$ pred: \% predicted; FVC: forced vital capacity; CT: computed tomography.

\#: FEV1/FVC <LLN; ": statistically significant.

(current or former smoker) proved to be significant predictive factors for the progression of 15th percentile (table 3). A 0.25 lower baseline KCO (being the SD of KCO in this sample) predicted an additional 1.6 HU lower 15th percentile after follow-up $(\mathrm{p}<0.001)$. The effect of KCO is illustrated in figure 2 . The effects of the other significant covariates in the model are listed in table 3. Age, height, BMI and pack-yrs smoked were not significantly associated with 15th percentile progression.

An additional analysis was performed to test whether the association of KCO with 15th percentile progression was independent of the baseline level of FEV1/FVC. An interaction term between baseline FEV1/FVC and baseline KCO was inserted in the statistical model. The baseline FEV1/FVC value was significantly $(p<0.001)$ associated with progression of 15 th percentile; a $1 \%$ lower baseline KCO value predicted an additional $0.3 \mathrm{HU}$ lower 15th percentile. However, the interaction term was not significant $(p=0.099)$ indicating that the association of baseline KCO was similar in participants with different levels of airflow obstruction.

Using the \%-950 HU approach as measure of emphysema severity yielded similar results as using the 15th percentile (see online supplementary material).

\section{Association of Kco with decline in FEV1/FVC}

Mean absolute \pm SD FEV1/FVC after follow-up was 70.2 $\pm 9.4 \%$. The statistical model explained $80 \%$ of the variance in FEV1/ FVC after follow-up $\left(\mathrm{r}^{2}=0.80\right)$. Baseline values of FEV1/FVC and $\mathrm{KCO}$ proved to be significant predictive factors for FEV1/ FVC decline as shown in table 4 . Adjusted decline was $1.44 \pm 0.92 \%$ during 3 -yr follow-up. To put this decline in 

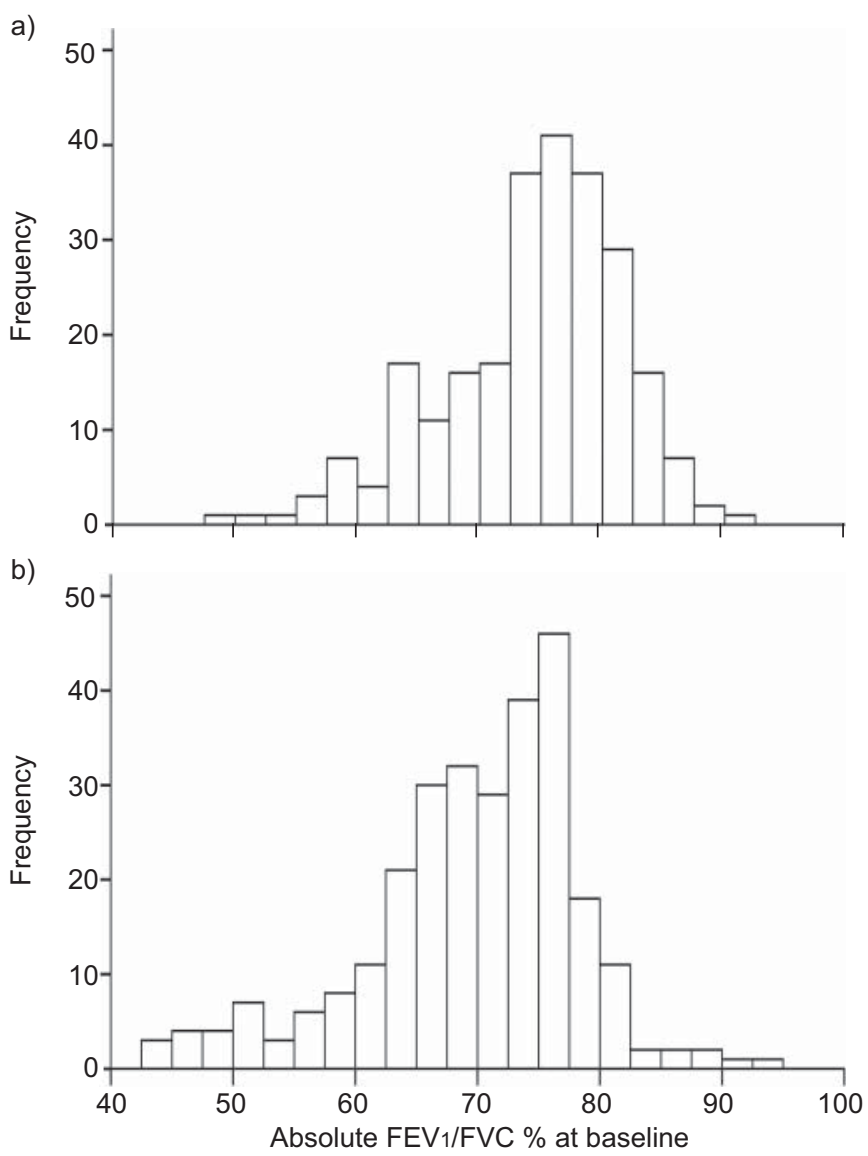

FIGURE 1. Histograms of absolute forced expiratory volume in $1 \mathrm{~S}\left(\mathrm{FEV}_{1}\right)$ / forced vital capacity (FVC) values for participants stratified by a) transfer coefficient of the lung for carbon monoxide $(K C O)>$ lower limit of normal (LLN) and b) KCO $<L L N$.

perspective, the expected 3-yr decline in FEV1/FVC according to appropriate reference values is $0.5 \%$ [10]. When a subject showed a 0.25 lower KCO (being 1 SD) compared with another subject, that subject suffered from an additional $0.78 \%$ lower FEV1/FVC after follow-up ( $<<0.001)$ (table 4, and fig. 3).

The analysis with insertion of an interaction term between baseline FEV1/FVC and baseline KCO showed that the association of KCO with FEV1/FVC decline was independent of the baseline FEV1/FVC value as the interaction term was not significant $(\mathrm{p}=0.133)$.

\section{DISCUSSION}

In the present study, we showed that a lower KCO value was associated with an increase of CT-quantified emphysema and a larger decline in FEV1/FVC during a 3-yr follow-up of male heavy-smokers. This association proved to be independent of the level of FEV1/FVC. KCO, a simple and patient-friendly measurement, may therefore help to detect current and former smokers who are susceptible to a more rapid progression of CT-quantified emphysema and decline in lung function independently of their FEV1/FVC level.

Parameters like the FEV1/FVC do not reflect the presence or the severity of emphysema accurately [23]. Mild emphysema does not always lead to a FEV1/FVC $<70 \%$ (or $<$ LLN), and thus COPD can be missed if only spirometry is performed. However, in daily practice the evaluation of subjects at risk for (or with established) COPD is usually based on spirometry [10]. Unfortunately, spirometry fails to discriminate between chronic bronchitis and emphysema. The latter may be assessed by CT scanning; however, a disadvantage of CT scanning is that it exposes subjects to radiation and is relatively expensive. It is therefore not performed on a regular basis, which is also true for repeatedly performed low-dose CT scans. An advantage of CTscanning is the additional information that is obtained on the distribution of emphysema, but it is questionable whether this information is clinically relevant [24]. Conversely, diffusion testing is harmless, less expensive and can thus be applied routinely and more frequently than CT scanning. This is strengthened by the finding that of the 272 participants with a KCO below the LLN, only 71 had an FEV1/FVC below the LLN. This finding again illustrates that in an at-risk population with a high smoking history, performing only spirometry may miss a large number of subjects with abnormal diffusion tests results.

The association of a lower baseline KCO with progression of emphysema and decline of FEV1/FVC was independent of the level of baseline FEV1/FVC as there were no significant interactions between them. This is an important finding because it illustrates that it is useful to perform KCO measurements in heavy smokers, independently of their FEV1/FVC. Only taking in account the FEV1/FVC, and not the KCO, in the evaluation of heavy smokers may result in missing subjects who will suffer from a stronger progression of 15 th percentile. The assessment of KCO thus may have important prognostic implications.

To our knowledge, there are no longitudinal studies examining the predictive value of $\mathrm{KCO}$ on FEV1/FVC decline. One study has examined the predictive value of the diffusion coefficient

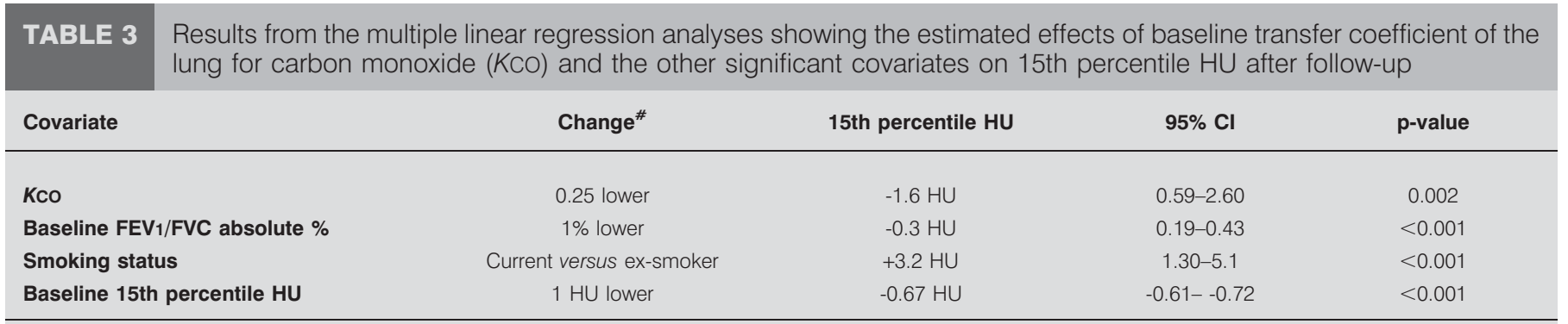

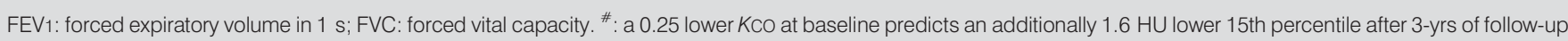




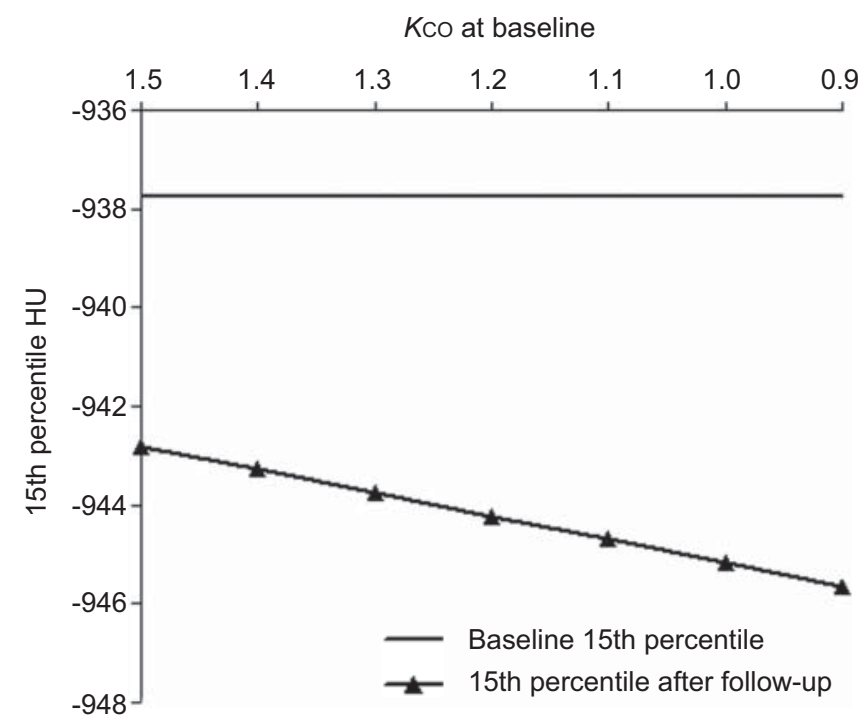

FIGURE 2. Relationship of baseline transfer coefficient of the lung for carbon monoxide $(K \mathrm{CO})$ and 15 th percentile after follow-up. This situation represents participants with a baseline age of $60.1 \mathrm{yrs}$, smoking history of 41.3 pack-yrs, height of $1.75 \mathrm{~m}$, forced expiratory volume in $1 \mathrm{~s} /$ forced vital capacity of $71.6 \%$ and a 15th percentile of $937.8 \mathrm{HU}$, which are the mean values of the study population at baseline. It can be seen that a lower $K \mathrm{co}$ at baseline predicts a more rapid decline of 15 th percentile, e.g. worsening of computed tomography-quantified emphysema. As an illustration: a Kco value of 1.2 at baseline associates with a follow-up 15th percentile of $-944.2 \mathrm{HU}$, while a Kco value of 1.4 at baseline associates with a follow-up 15th percentile of $-943.3 \mathrm{HU}$, despite similar age, height, pack-yrs smoking and 15th percentile levels of these individuals at baseline.

of the lung for carbon monoxide $(\mathrm{DL}, \mathrm{CO})$ on $\mathrm{FEV} 1$ decline and showed that $D \mathrm{~L}, \mathrm{CO}$ differentiates smokers who will experience a rapid FEV1 decline [25]. The included subjects were comparable with our population. They were also relatively healthy but slightly younger. Although these authors measured the $D \mathrm{~L}, \mathrm{CO}$ instead of the KCO, their results support our findings that the KCO may help to identify subjects with a more rapid lung function decline.

As for the association between $\mathrm{KCO}$ and lung function decline, literature evaluating the predictive value on emphysema progression is scarce. Cross-sectional studies have shown that the $\mathrm{KCO}$ is lower in subjects with pathologically defined as well as with CT-detected emphysema [26-28]. We confirm these findings by showing that there was a significant correlation between $\mathrm{KCO}$ and 15th percentile at baseline $(\mathrm{r}=0.23)$. However, the correlation was not as strong as previously reported, which

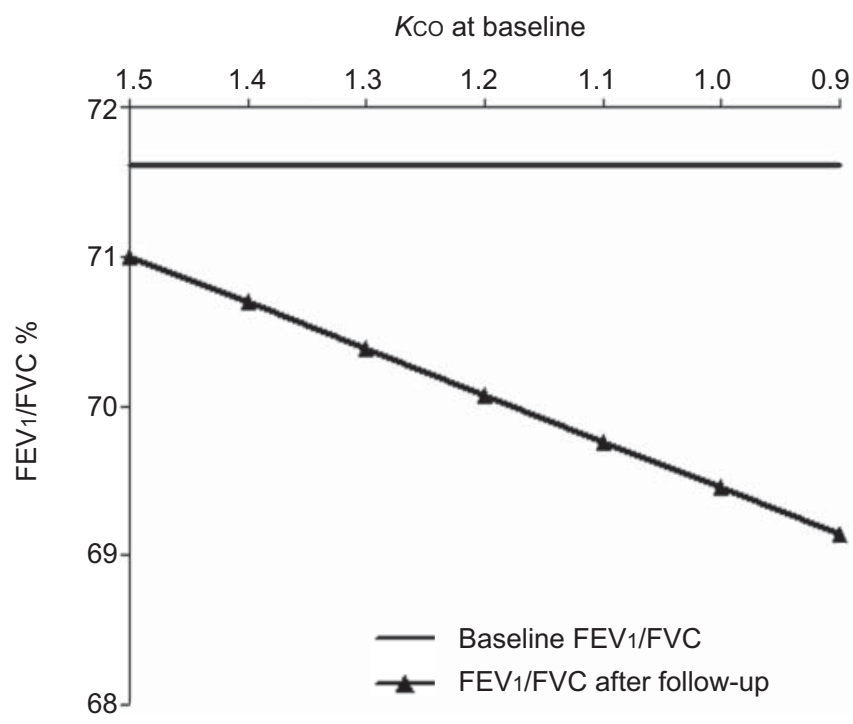

FIGURE 3. Relationship of baseline transfer coefficient of the lung for carbon monoxide $(K C O)$ and forced expiratory volume in $1 \mathrm{~s}(\mathrm{FEV} 1)$ /forced vital capacity (FVC) after follow-up. This situation represents participants with a baseline age of $60.1 \mathrm{yrs}, 41.3$ pack-yrs, height of $1.75 \mathrm{~m}, \mathrm{FEV} 1 / \mathrm{FVC}$ of $71.6 \%$ and a 15 th percentile of $937.8 \mathrm{HU}$, which are the mean values of the study population at baseline. It can be seen that a lower $K \mathrm{CO}$ at baseline predicts a larger decline in $\mathrm{FEV}_{1} / \mathrm{FVC}$. As an illustration: a KCO value of 1.2 at baseline associates with a follow-up FEV $1 / F V C$ of $70.07 \%$, while a $K \mathrm{KCO}$ value of 1.4 at baseline associates with a follow-up FEV1/FVC of $70.69 \%$, despite similar age, height, pack-yrs smoking and 15th percentile levels of these individuals at baseline.

may be due to the fact that the included subjects were relatively healthy and without severe emphysema.

There are a number of strengths to our study. First, emphysema scores were automatically quantified, which eliminates interobserver variability known to be present in the visual assessment of emphysema. Secondly, the study was performed in one centre and only one type of CT scanner was used, excluding possible scanner bias due to different algorithms used by different types of CT scanners. Thirdly, the same diffusion testing equipment was used. This is especially important since it is known that large variability may exist in KCO measurements between different lung function laboratories [29]. Fourthly, only heavy smoking, but relatively healthy participants were included. This makes the results especially applicable to subjects who are at risk of progression of emphysema and airflow obstruction. The earlier-mentioned cross-sectional studies were almost all restricted to (severe) COPD subjects. Finally, because

\begin{tabular}{|c|c|c|c|c|}
\hline Kco & 0.25 lower & $-0.78 \%$ & $0.31-1.14$ & $<0.001$ \\
\hline Baseline FEV $1 / F V C$ absolute \% & $1 \%$ lower & $-0.90 \%$ & $0.85-0.94$ & $<0.001$ \\
\hline
\end{tabular}


of the large sample size, we could extensively correct for potential confounding factors like age, pack-yrs smoked and smoking status. This makes our reported results more precise.

This study also has some limitations. First, only pre-bronchodilator spirometry was obtained, which could have resulted in lower measured FEV1/FVC values. As a result, the percentage of participants without airflow obstruction could actually be lower. However, because we treated FEV1/FVC as quantitative we do not expect that this has affected our results. Secondly, no females were included due to the inclusion criteria of the study. This is unfortunate because the prevalence of COPD is increasing in females. Previous studies showed that emphysema scores in females are lower than in males, and that females also show lesser progression of emphysema after follow-up [30-32]. Lastly, we performed analyses with both the 15th percentile and the \%-950 HU; the results of the latter are described in the online supplementary material. The outcomes of the analyses with \%-950 HU as emphysema measurement are in the similar direction as by using 15th percentile and underscore our conclusions. It should, however, be realised that the 15th percentile takes into account not only the regions with markedly reduced density, but the whole lung, while the \%-950 HU is less sensitive for lung density changes of the whole lung.

In conclusion, we have shown that current and former heavy smokers with lower baseline KCO values show a significantly greater progression of CT-quantified emphysema and decline in FEV1/FVC. These results show that the KCO may be a useful measurement in the evaluation and follow-up of heavysmoking subjects, with or without airflow obstruction.

\section{SUPPORT STATEMENT}

This work was supported by EU FP7 grant number 201379, COPACETIC study.

\section{STATEMENT OF INTEREST}

None declared.

\section{REFERENCES}

1 Murray CJ, Lopez AD. Alternative projections of mortality and disability by cause 1990-2020: Global Burden of Disease Study. Lancet 1997; 349: 1498-1504.

2 Brenner DJ, Hall EJ. Computed tomography - an increasing source of radiation exposure. N Engl J Med 2007; 357: 2277-2284.

3 Hughes JM, Pride NB. In defence of the carbon monoxide transfer coefficient KCO (TL/VA). Eur Respir J 2001; 17: 168-174.

4 Holme J, Stockley RA. Radiologic and clinical features of COPD patients with discordant pulmonary physiology: lessons from alpha1-antitrypsin deficiency. Chest 2007; 132: 909-915.

5 van der Lee I, Gietema HA, Zanen P, et al. Nitric oxide diffusing capacity versus spirometry in the early diagnosis of emphysema in smokers. Respir Med 2009; 103: 1892-1897.

6 van Iersel CA, de Koning HJ, Draisma G, et al. Risk-based selection from the general population in a screening trial: selection criteria, recruitment and power for the Dutch-Belgian randomised lung cancer multi-slice CT screening trial (NELSON). Int J Cancer 2007; 120: $868-874$

7 van Klaveren RJ, Oudkerk M, Prokop M, et al. Management of lung nodules detected by volume CT scanning. N Engl J Med 2009; 361: 2221-2229.

8 Miller MR, Hankinson J, Brusasco V, et al. Standardisation of spirometry. Eur Respir J 2005; 26: 319-338.
9 MacIntyre N, Crapo RO, Viegi G, et al. Standardisation of the single-breath determination of carbon monoxide uptake in the lung. Eur Respir J 2005; 26: 720-735.

10 Quanjer PH, Tammeling GJ, Cotes JE, et al. Lung volumes and forced ventilatory flows. Report Working Party Standardization of Lung Function Tests, European Community for Steel and Coal. Official Statement of the European Respiratory Society. Eur Respir J 1993; 6: Suppl. 16, 5-40.

11 Jones RS, Meade F. A theoretical and experimental analysis of anomalies in the estimation of pulmonary diffusing capacity by the single breath method. Q J Exp Physiol Cogn Med Sci 1961; 46: 131-143.

12 Stam H, Hrachovina V, Stijnen $\mathrm{T}$, et al. Diffusing capacity dependent on lung volume and age in normal subjects. J Appl Physiol 1994; 76: 2356-2363.

13 Cotes JE, Chinn DJ, Quanjer PH, et al. Standardization of the measurement of transfer factor (diffusing capacity). Report Working Party Standardization of Lung Function Tests, European Community for Steel and Coal. Official Statement of the European Respiratory Society. Eur Respir J 1993; 6: Suppl. 16, $41-52$.

14 Gierada DS, Yusen RD, Pilgram TK, et al. Repeatability of quantitative CT indexes of emphysema in patients evaluated for lung volume reduction surgery. Radiology 2001; 220: 448-454.

15 Newell JD Jr, Hogg JC, Snider GL. Report of a workshop: quantitative computed tomography scanning in longitudinal studies of emphysema. Eur Respir J 2004; 23: 769-775.

16 Shaker SB, Maltbaek N, Brand P, et al. Quantitative computed tomography and aerosol morphometry in COPD and $\alpha_{1}$-antitrypsin deficiency. Eur Respir J 2005; 25: 23-30.

17 Sverzellati N, Calabro E, Randi G, et al. Sex differences in emphysema phenotype in smokers without airflow obstruction. Eur Respir J 2009; 33: 1320-1328.

18 van Rikxoort EM, de Hoop B, Viergever MA, et al. Automatic lung segmentation from thoracic computed tomography scans using a hybrid approach with error detection. Med Phys 2009; 36: 2934-2947.

19 van Rikxoort EM, Prokop M, de Hoop B, et al. Automatic segmentation of the pulmonary lobes from fissures, airways, and lung borders: evaluation of robustness against missing data. Med Image Comput Comput Assist Interv 2009; 12: 263-271.

20 Gould GA, MacNee W, McLean A, et al. CT measurements of lung density in life can quantitate distal airspace enlargement - an essential defining feature of human emphysema. Am Rev Respir Dis 1988; 137: 380-392.

21 Parr DG, Stoel BC, Stolk J, et al. Influence of calibration on densitometric studies of emphysema progression using computed tomography. Am J Respir Crit Care Med 2004; 170: 883-890.

22 Parr DG, Sevenoaks M, Deng C, et al. Detection of emphysema progression in alpha 1-antitrypsin deficiency using CT densitometry; methodological advances. Respir Res 2008; 9: 21.

23 Hogg JC, Wright JL, Wiggs BR, et al. Lung structure and function in cigarette smokers. Thorax 1994; 49: 473-478.

24 Gietema HA, Zanen P, Schilham A, et al. Distribution of emphysema in heavy smokers: impact on pulmonary function. Respir Med 2010; 104: 76-82.

25 Cauberghs M, Clement J, Van de Woestijne KP. Functional alterations accompanying a rapid decline in ventilatory function. Am Rev Respir Dis 1993; 147: 379-384.

26 Morrison NJ, Abboud RT, Ramadan F, et al. Comparison of single breath carbon monoxide diffusing capacity and pressure-volume curves in detecting emphysema. Am Rev Respir Dis 1989; 139: 1179-1187.

27 Gould GA, Redpath AT, Ryan M, et al. Lung CT density correlates with measurements of airflow limitation and the diffusing capacity. Eur Respir J 1991; 4: 141-146. 
28 Cerveri I, Dore R, Corsico A, et al. Assessment of emphysema in COPD: a functional and radiologic study. Chest 2004; 125: 1714-1718.

29 Jensen R, Leyk M, Crapo R, et al. Quality control of DL,CO instruments in global clinical trials. Eur Respir J 2009; 33: 828-834.

30 Bellomi M, Rampinelli C, Veronesi G, et al. Evolution of emphysema in relation to smoking. Eur Radiol 2010; 20: 286-292.
31 Grydeland TB, Dirksen A, Coxson $\mathrm{HO}$, et al. Quantitative computed tomography: emphysema and airway wall thickness by sex, age and smoking. Eur Respir J 2009; 34: 858-865.

32 Martinez FJ, Curtis JL, Sciurba F, et al. Sex differences in severe pulmonary emphysema. Am J Respir Crit Care Med 2007; 176: 243-252. 